\title{
Expansão Agrícola, Preços e Apropriação de Terra Por Estrangeiros no Brasil ${ }^{1}$
}

\author{
Sérgio Sauer ${ }^{2}$ e Sergio Pereira Leite $^{3}$
}

Resumo: A recente "corrida mundial por terras" transformou a América Latina, em geral, e o Brasil, em particular, em alvos preferenciais para negócios com aumento considerável de investimentos estrangeiros no setor agropecuário, inclusive na compra de terras, com a participação de empresas do setor financeiro. Mesmo sendo um mercado de baixa liquidez, negócios com terras não são novidade no Brasil, mas têm aumentado consideravelmente após 2002, sendo, inclusive, possível perceber esse processo no sistema de cadastro do Instituto Nacionalde Colonização e Reforma Agrária (Incra). De acordo com pesquisas de campo, a maioria dos investimentos recentes está relacionada à produção de grãos (principalmente soja) e de cana-de-açúcar (produção de açúcar e etanol), mas tambémà mineração, resultando em aumento dos preços da terra, entre outras consequências em algumas regiões do Brasil. Essa "corrida por terra" levou o governo federal a restabelecer um mecanismo legal para "controlar" esses investimentos estrangeiros em terra. O presente artigo discute esse processo recente de investimentos na compra de terras no Brasil, investigando causas para tais investimentos e suas principais consequências, incluindo possíveis influências sobre os preços da terra e impactos sociais e políticos nas históricas disputas pelo acesso à terra no Brasil.

Palavras-chaves: Terra, mercado de terra, estrangeirização, preços, fronteiras agrícolas, expansão agrícola, Brasil.

\begin{abstract}
The recent "rush for farmland" in the world has made of Latin America and Brazil targets in the process of land deals with a great increase of foreign investments on the agribusiness including land purchases by financial companies, among others. Despite the low liquidity, land deals and foreign investments in agribusiness are not new in Brazil, but have increased considerably after 2002, as it is possible to be seenin the registration

1 Os autores agradecem os comentários dos pareceristas anônimos da revista. Como de praxe, as informações e os argumentos apresentados são de inteira responsabilidade dos autores.

2 Doutor em Sociologia e professor da Faculdade da UnB de Planaltina (FUP/UnB), do Programa de Pós-graduação em Meio Ambiente e Desenvolvimento Rural (PPG-Mader/FUP), do Propaga (FAV/ UnB) e Relator do Direito Humano à Terra, Território e Alimentação (Plataforma DhESCA Brasil). E-mail:sauer.sergio@gmail.com

3 Professor do Programa de Pós-graduação de Ciências Sociais em Desenvolvimento, Agricultura e Sociedade (CPDA), da Universidade Federal Rural do Rio de Janeiro (UFRRJ) e coordenador do Observatório de Políticas Públicas para a Agricultura (OPPA).E-mail:sergioleite@ufrrj.br
\end{abstract}


system of the National Institute for Colonization and Agrarian Reform. According to some field researches, most of the recent investments are related to production of grains (especially soybean) and sugarcane (to produce sugar and ethanol), but also for mining, resulting, among other consequences, in a great increase of land prices in some Brazilian regions. Such rush for land has led the Brazilian government to reestablish a legal mechanism to "control" these foreign investments in land deals. This article discussesthe recent process of foreign investments in purchasing land in Brazil, focusing inmain causes for such investments and its consequences, including possible influences on land prices and social and political impacts over disputes to access land in Brazil.

Key-words: Land market, land grabbing, land price, agriculture frontier, Brazil.

Classificação JEL: Q13, Q15, Q24, R52.

\section{Introdução}

A retórica sobre um crescimento recente do interesse e busca por terras em todo o mundo, especialmente em razão da demanda por alimentos, agroenergias e matérias-primas, está presente na grande imprensa e tem sido fruto de debates acadêmicos internacionais. Segundo estudo do Banco Mundial, de 2010, a demanda mundial por terras tem sido enorme, especialmente a partir de 2008, tornando a "disputa territorial" um fenômeno global (BORRAS et al., 2011; FERNANDES, 2011). A transferência de terras agricultáveis (ou terras cultivadas) era da ordem de quatro milhões de hectares por ano antes de 2008 , sendo que, entre outubro de 2008 e agosto de 2009, teriam sido comercializados mais de 45 milhões de hectares, $75 \%$ destes na África e outros 3,6 milhões de hectares no Brasil e Argentina (BANCO MUNDIAL, 2010), impulsionando aquilo que se convencionou chamar de "land grabbing", "acaparamiento" ou "extranjerización" de terras (BORRAS et al., 2011).

Em consequência de investimentos produtivos ou especulativos, o estudo do Banco Mundial afirma que o crescimento da produção agrícola e, consequentemente, das demandas e transações de terras, se concentra na expansão de oito commodities: milho, soja, cana-de-açúcar, dendê (óleo), arroz, canola, girassol e floresta plantada, sendo que a participação brasileira se dá fundamentalmente nos três primeiros produtos (BANCO MUNDIAL, 2010). Um dos dados mais significativos nesse estudo do Banco Mundial é a caracterização dos atuais demandantes de terras no mundo, chamando a atenção os investimentos do setor financeiro, historicamente avesso à imobilização de capital, especialmente na compra de terra, um mercado caracterizado pela baixa liquidez.

O interesse global por terras, associado à demanda mundial por commodities agrícolas e não agrícolas e à valorização dessas no mercado internacional, tem provocado uma elevação dos preços. Constatado pelo citado estudo do Banco Mundial (2010), o aumento de preço das terras brasileiras também vem sendo regularmente anunciado como um dos efeitos desse processo (FERNANDES, 2011). No entanto, não há estudos sistemáticos capazes de oferecer um panorama nacional das transações e preços, inclusive porque são "negócios privados" e as informações não são disponibilizadas, sendo que notícias são, geralmente, ilustradas com levantamentos de casos exemplares e dados locais ou municipais.

O presente artigo aborda cinco aspectos contendo elementos ainda pouco tratados pela literatura especializada. $\mathrm{O}$ primeiro item discorre sobre a demanda histórica por terra no País, chamando atenção para a persistência da concentração fundiária em pleno século XXI, a partir dos dados do Censo Agropecuário de 2006. O segundo tópico dedica-se a examinar o processo de expansão do chamado "agronegócio" brasileiro, centrando-se particularmente nos movimentos espaciais das culturas de cana-de-açúcar e soja e seu rebatimento em regiões ditas de "fronteira agrícola". Parte desse processo, que orientou especialmente investimentos na área de produção de biomassa, está lastreada na participação do capital internacional e suas inversões nos ativos 
fundiários, tema que é objeto do item seguinte. O quarto ponto do artigo aborda a repercussão desses aspectos sobre o comportamento do mercado de terras, em particular de algumas regiões reconhecidamente objeto da expansão de monoculturas e commodities. Finalmente, precedendo as considerações finais, tratamos de recuperar medidas governamentais recentes sobre o acesso à terra por empresas e pessoas estrangeiras, especialmente a publicação de novo Parecer da Advocacia Geral da União (AGU).

\section{Dinâmica fundiária: a histórica demanda por terras no Brasil}

Não é nenhuma novidade que o Brasil possui uma estrutura de propriedade da terra altamente concentrada, confirmada pelos dados do Censo Agropecuário, de 2006, do IBGE (Instituto Brasileiro de Geografia e Estatística). Essa concentração tem origem nos tempos coloniais, apesar de ter sido agravada a partir dos anos 1960, com a implantação da Revolução Verde e do atual modelo agropecuário, baseado na modernização de grandes extensões de terras (FERNANDES, 2011). Segundo Dias et al. (2001), historicamente

a legislação fundiária brasileira estimulava a ocupação com as facilidades oferecidas para a regularização de suas posses (apenas sinais de ocupação bastavam para garantir a posse legal), assim como pela ausência efetiva de limites ao tamanho da posse (p. 12)

e a total falta de tributação da propriedade fundiária.

O Brasil, em sua extensão continental, detém 850 milhões de hectares de terras, sendo que um pouco mais dametade (436,60 milhões de hectares, ou $51,35 \%$ ) está cadastrada no Sistema Nacional de Cadastro Rural (SNCR), do Incra, como imóveis rurais. Excluindo-se as unidades de conservação ambiental (102,06 milhões de hectares em parques nacionais, reservas extrativistas, florestas nacionais etc.), as áreas indígenas (128,47 milhões de hectares), as terras públicas formalizadas $(4,20$ milhões de hectares) e os perímetros urbanos e de infraestrutura (estradas, hidrelétricas etc.), há au- sência de 172,95 milhões de hectares que devem ser consideradas terras devolutas (SAMPAIO et al., 2003). Essa ausência é confirmada na versão oficial do II Plano Nacional de Reforma Agrária (PNRA), que afirma que " $50,86 \%$ da área total do território brasileiro está na condição de cadastrada" (BRASIL, 2005, p. 22). Isso significa que não há registros formais em nenhum dos instrumentos oficiais de titularidade de terras de aproximadamente $20 \%$ do território brasileiro (SAMPAIO et al., 2003).

Se tomarmos a situação fundiária da Amazônia Legal, os dados são ainda mais alarmantes, pois a falta de registros sobe para $24 \%$ (WILKINSON et al., 2010) e,do total de 509 milhões de hectares, 178 milhões são ocupados de forma privada ( $35 \%$ do total cadastrado). No entanto, desses 178 milhões de hectares

[...] declarados como propriedades privadas, 100 milhões de hectares podem estar baseados em documentação fraudulenta. Outros 42 milhões de hectares dessa área são classificados a partir de declarações cadastrais como posse, que podem ou não ser passíveis de regularização fundiária, novamente dependendo das suas circunstâncias de tamanho, história e localização. Dessa forma, $30 \%$ da área pode ser legalmente incerta e/ou contestada (WILKINSON et al., 2010, p. 15).

Um dos resultados disso são as

situações de apropriação ilegal de terras devolutas ou mesmo já arrecadadas, e irregularidades no Cadastro que permitem que, em alguns casos, a área dos imóveis cadastrados supere a própria área total do estado (BRASIL, 2005, p. 22).

Associada às fragilidades cadastrais e à apropriação ilegal, está a clássica concentração da propriedade da terra no Brasil, inclusive favorecida pela completa falta de tributação fundiária ${ }^{4}$.

\footnotetext{
4 Segundo Sabbato (2008), a reforma operada no Imposto Territorial Rural (ITR), em 1996, não surtiu o efeito desejado de acoplar esse instrumento de política fiscal ao
} 
Tabela 1. Número e área dos estabelecimentos por grupos de área total - Brasil - 2006.

\begin{tabular}{lcccc}
\hline \multicolumn{1}{c}{ Grupos de área total } & $\begin{array}{c}\text { Número de estabelecimentos } \\
\text { (unidades) }\end{array}$ & $\%$ & $\begin{array}{c}\text { Área dos estabelecimentos } \\
\text { (hectares) }\end{array}$ & \% \\
\hline Menos de 10 hectares & 2.477 .071 & 47,86 & 7.798 .607 & 2,36 \\
10 a menos de 100 hectares & 1.971 .577 & 38,09 & 62.893 .091 & 19,06 \\
100 a menos de 1.000 ha & 424.906 & 8,21 & 112.696 .478 & 34,16 \\
1.000 ha e mais & 46.911 & 0,91 & 146.553 .218 & 44,42 \\
Total & 5.175 .489 & 100,00 & 329.941 .393 & 100,00 \\
\hline
\end{tabular}

Fonte: IBGE, censo agropecuário 2006 (BRASIL, 2009, p. 107).

Os dados do último censo agropecuário, de 2006 (BRASIL, 2009), realizado pelo IBGE, confirmam que a concentração fundiária em grandes estabelecimentos agropecuários acima de mil hectares não se alterou nos últimos 20 anos (cf. informações contidas nos censos de 1985, 1995 e 2006). O índice de Gini manteve-se praticamente o mesmo no período, e o Brasil ainda apresenta alto grau de concentração fundiária, expresso por 0,857 , em 1995/96, e 0,856, em 2006 (HOFFMANN e NEY, 2010).

Segundo dados do censo agropecuário de 2006, as propriedades com menos de dez hectares representam mais de $47 \%$ do total de estabelecimentos, mas ocupam apenas $2,7 \%$ da área total dos estabelecimentos rurais, ou seja, 7,8 milhões de hectares. Na outra ponta do espectro fundiário, os estabelecimentos com áreas acima de mil hectares somam apenas $0,91 \%$ do número total de estabelecimentos, mas detêm mais de $43 \%$ da área total, concentrando 146,6 milhões de hectares (LEITE e ÁVILA, 2007).

Esses dados sobre a concentração possuem ainda uma dimensão importante, ou seja, a histórica demanda por terras no Brasil por parte daqueles segmentos que, mesmo centrando no meio rural suas expectativas de vida, produção, consumo e conquista da cidadania, sempre estiveram excluídos do acesso às mesmas, acesso que favoreceria uma distribuição mais equânime dos imóveis rurais, aliados aos processos de justiça social e democratização fundiária (LEITE et al., 2004;

programa de reforma agrária, sendo que a estimativa desse autor para a evasão fiscal do ITR em 1997 foi de 90,3\% (SABBATO, 2008, p. 121).
LEITE e ÁVILA, 2007). De acordo com estimativas do II PNRA, cerca de três milhões de estabelecimentos (todos com menos de dez hectares) possuem terra, mas com área insuficiente para gerar renda, sustentar as famílias e garantir um mínimo de qualidade de vida no campo (BRASIL, 2005, p. 18). Havia, em 1997, "um montante de 3,1 milhões de famílias" sem-terra, ${ }^{5}$ sendo que esse dado corresponde "aos trabalhadores rurais sem acesso à terra, não incorpora os pequenos produtores agrícolas - proprietários, parceiros ou arrendatários" (BRASIL, 2005, p. 17), ampliando a histórica demanda por terra no Brasil.

De acordo com informações do Incra, dos 436,60 milhões de hectares cadastrados no SNCR, 120,4 milhões de hectares foram declarados pelos responsáveis dos estabelecimentos como improdutivos (SAMPAIO et al., 2003). Esse dado levou Wilkinson et al. (2010) a afirmarem que "há muita terra ociosa ou com um baixíssimo grau de utilização (p. 14)" no Brasil. Em outras palavras, mais de $14 \%$ das terras cadastradas no órgão responsável poderiam se constituir no estoque (oferta) para atender à demanda por terras provenientes de trabalhadores sem-terra.

Ainda que o assunto seja polêmico, a expansão agrícola em direção aos Cerrados e à Amazônia tem gerado protestos de organizações ambientalistas e comunidades nativas, visto que parte da área ocupada pela soja tem sido angariada às custas do

5 De acordo com o II PNRA, ademanda explícita por reforma agrária, em 2005, podia "ser identificada pelo cadastro resultante das inscrições via Correio no 'Programa de Acesso à Terra' e outras formas de cadastramento, como é o caso daqueles efetuados na Sala do Cidadão, chegava a um total de 839.715 cadastros" (BRASIL, 2005, p. 17), ou seja, quase 900 mil famílias demandando terra diretamente. 
desmatamento e/ou do deslocamento forçado de agricultores familiares ou aldeias indígenas, como pode ser constatado nas chapadas piauienses. Não é à toa a forte pressão dos empresários rurais sobre a legislação ambiental (Código Florestal, Área de Reserva Legal, Área de Preservação Permanente, Sistema Nacional de Unidades de Conservação) e aquela voltada aos direitos sociais de comunidades nativas, mormente ocupadas de forma tradicional/coletiva (quilombos, terras indígenas, fundos de pasto, áreas extrativistas etc.), em busca da abertura de novas frentes de expansão, em especial nas regiões de Cerrado e do bioma amazônico (SAUER, 2011).

Em se tratando de acesso à terra, é fundamental reconhecer, ainda, que vigora uma situação de ilegalidade e instabilidade jurídica no Brasil, facultando aquilo que Delgado (2005) denominou de "frouxidão da política agrária", rebatendo inclusive no processo de apropriação de terras por estrangeiros. Conforme já mencionado, a legislação brasileira nunca estabeleceu qualquer limite à propriedade da terra (DIAS et al., 2001), nem mesmo para pessoas físicas e jurídicas estrangeiras, apesar da edição da Lei n. 5.709, de $1971^{6}$. As restrições nunca tiveram efeito prático, especialmente pela falta de fiscalização e controle sobre as aquisições de terras, inclusive devido à distância entre o discurso nacionalista e as políticas de abertura ao capital internacional do regime mili$\operatorname{tar}$ (OLIVIERA, 2010).

Segundo o Banco Mundial (2010), a expansão da produção agrícola mundial e, em consequência, também as transações de terras e o que a literatura vem denominando de "land grabbing" ou "acaparamiento de terras", 7 se deu devido: a) à

6 A Lei n. 8.629, de 1993, no artigo 23, § 1ํo, faz restrições ao arrendamento de terras a estrangeiros.

7 Essa expressão vem sendo empregada nos estudos na área, caracterizando um processo de apropriação de grandes parcelas de terra pelo capital estrangeiro. Para Merlet (2010), esse processo não pode ser reduzido ao mecanismo de negócio, pressupondo o simples funcionamento do mercado de compra e venda de imóveis rurais. Segundo o estudo encomendado pelo Comité Technique Foncieret Développement, há um movimento de "apropriação e concentração de terras - e recursos naturais - em larga escala" em nível mundial (MERLET, 2010). demanda por alimentos, ração, celulose e outros insumos industriais, em consequência do aumento populacional e da renda; b) à demanda por matérias-primas para os agrocombustíveis (reflexo das políticas e procura dos principais países consumidores) e c) ao deslocamento da produção de commodities para regiões com terra abundante, mais barata e com boas possibilidades de crescimento da produtividade, como é o caso do Brasil e de toda a América Latina (BORRAS et al., 2011).

\section{Expansão do agribusiness brasileiro: um breve resgate}

Com a crise internacional no início dos anos 1980, o setor rural brasileiro viu-se envolto no esforço de geração de superávits na balança comercial, aprofundando sua capacidade de exportação de produtos agroprocessados e gerando divisas canalizadas para o pagamento dos serviços da dívida externa. Apresentando um desempenho sempre positivo no saldo comercial (exportações - importações) ao longo desse período, o setor agropecuário voltou a ocupar, nos anos mais recentes, especialmente com a desvalorização do Real em 1999 (e mesmo com a nova valorização da moeda a partir de 2004), um papel de destaque nessa "ofensiva externa" (LEITE e WEZS, 2010).

$\mathrm{Na}$ última década, verificou-se uma vigorosa expansão da chamada "fronteira agrícola", incorporando áreas localizadas nos estados do Maranhão, Piauí, Tocantins (o "Mapito"), a Bahia, e outras inscritas na região Amazônica (HECHT, 2005). Esse processo de crescimento segue uma perspectiva global, pois, segundo estimativas do Banco Mundial (2010), em torno de $23 \%$ do crescimento da produção agrícola mundial se deu em função da expansão das "fronteiras agrícolas", apesar de que o aumento mais expressivo (cerca de 70\%) da produção é resultado do incremento da produtividade física.

A soja e a cana-de-açúcar são culturas sobejamente reconhecidas como representativas do "agronegócio", e sua expansão está entre as oito commodities responsáveis pelo aumento da produção agrícola, segundo estudo do Banco Mundial (2010). 
Figura 1. Expansão da produção de soja e localização das principais agroindústrias.
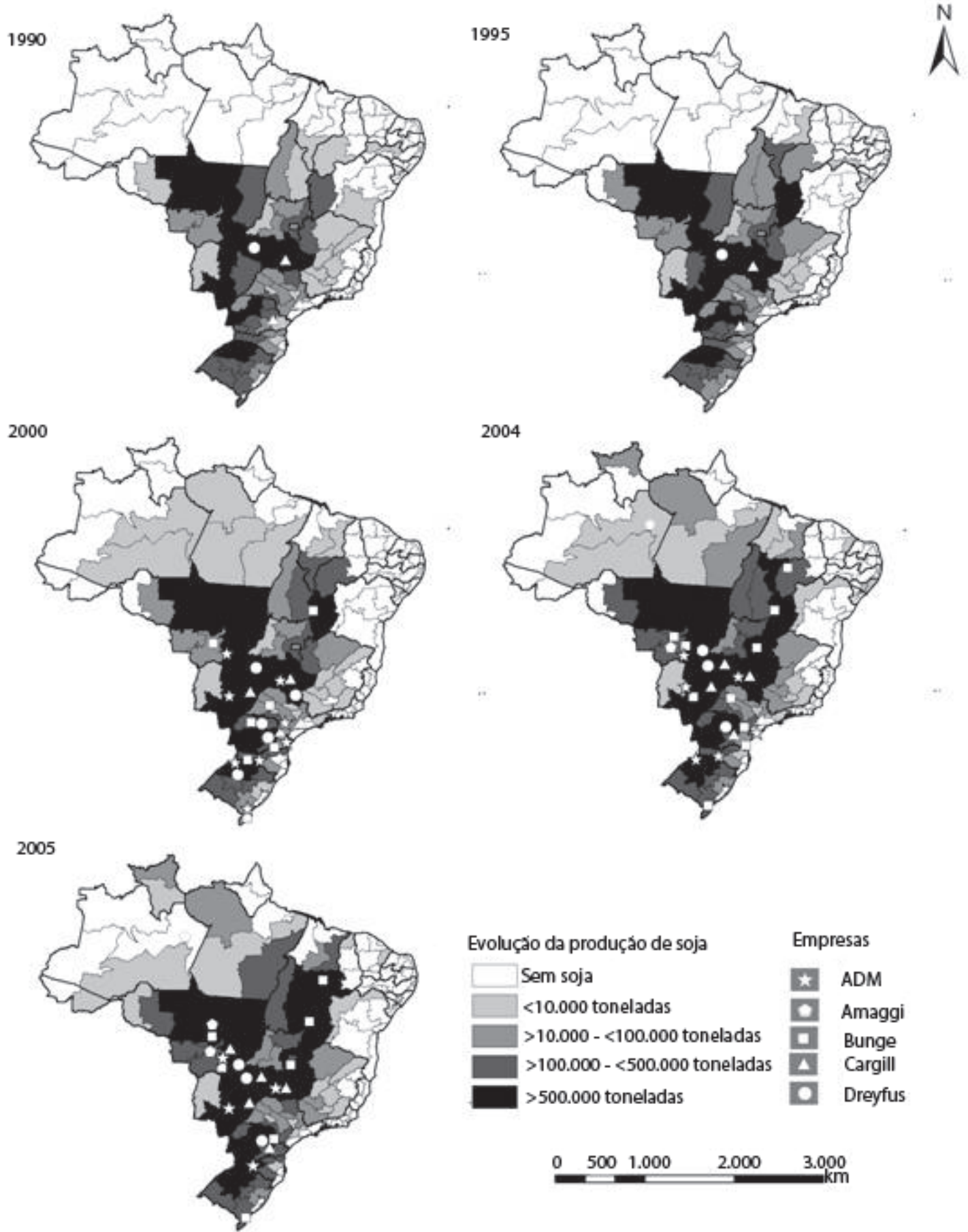

Empresas
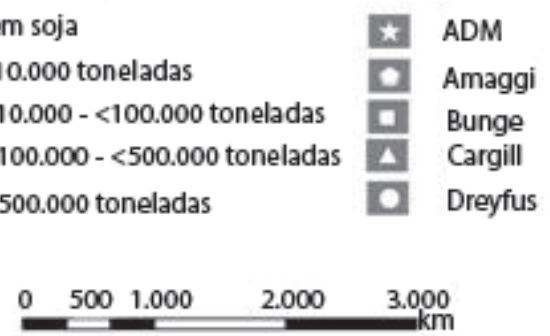

Fonte: Wesz Jr. (2008) e Heredia et al. (2010). ${ }^{1}$

1 Os autores agradecem a colaboração de Valdemar Wesz Jr. na elaboração dos cartogramas. Parte das informações trazidas nesses parágrafos está baseada em Heredia, Palmeira e Leite (2010). 
A Figura 1 ilustra o intenso processo de espacialização da produção de soja no País, entre 1980 e 2009, anteriormente concentrada na região Sul, para as áreas compreendidas pelos Cerrados, seja nos estados da região Centro-Oeste, seja em direção ao Cerrado mineiro ou aos Cerrados nordestinos. Mais recentemente, é possível verificar sua expansão para a região amazônica, especialmente nos estados do Amazonas (na região de Humaitá) e do Pará (sudeste e, em especial, oeste paraense, na região de Santarém) (LEITE e WEZS, 2010; HECHT, 2005; HEREDIA et al., 2010).

Pela mesma figura é possível verificar, ainda, as diferentes agroindústrias de esmagamento da soja para produção de farelo, óleo, ração e outros produtos derivados. Destacamos no mapa a localização das empresas multinacionais (tradings), em particular o chamado grupo ABCD (ADM, Bunge, Cargill, Dreyfus). A participação do capital internacional no total do capital aplicado no setor agroindustrial de esmagamento do grão, que era de $16 \%$ em 1995, sobe violentamente para $57 \%$ em 2005 , caracterizando um forte processo de concentração econômica e desnacionalização do setor.

Pode-se verificar um deslocamento geográfico na posição dessas empresas que alteram sua estratégia anterior (até o final dos anos 1990) de compra de antigas unidades de grupos empresariais nacionais, situadas na região Centro-Sul, para a construção de novas plantas industriais na área dos Cerrados na década atual, cujo "centrão" passa a concentrar $72 \%$ do valor da produção dessas unidades (HEREDIA et al., 2010; WESZ Jr., 2008).

Segundo Wilkinson et al. (2010), com essa expansão nota-se também o surgimento, cada vez mais frequente, de empresas especializadas na corretagem imobiliária vinculada à "limpeza", preparo e venda de novas áreas para grupos privados (nacionais e estrangeiros), o que vale tanto para o setor de grãos quanto para o setor sucroalcooleiro. Entre outras consequências há um processo de valorização dessas terras, resultando em aumento de preços (SAUER, 2011), conforme veremos adiante.

O mesmo processo de expansão territorial sobre áreas aproveitáveis tem ocorrido com o setor sucroalcooleiro, em especial com o forte aumento da área plantada com cana-de-açúcar nos estados de São Paulo, Minas Gerais, Mato Grosso do Sul, Goiás e Paraná. Essa expansão está orientada, em boa medida, para a produção de etanol, que constitui peça importante do Programa Nacional de Agroenergia, do Ministério da Agricultura, Pecuária e Abastecimento (Mapa), rivalizando ou complementando, dependendo da perspectiva - com outro programa direcionado ao fomento da produção de biodiesel, o Programa Nacional de Produção e Uso do Biodiesel (PNPB) (LEITE e WEZS, 2010; FERNANDES, 2011). A expansão da produção de cana pode ser visualizada na Figura 2, ficando evidente a concentração na região Sudeste (em especial São Paulo e Minas Gerais) e sua expansão em relação ao Mato Grosso do Sul, Goiás e Paraná, em detrimento de regiões "tradicionais" no plantio dessa commodities (o norte do estado do Rio de Janeiro e a Zona da Mata Pernambucana, o norte de Alagoas e o sul da Paraíba) (HEREDIA et al., 2010).

Além da polêmica que envolve o debate sobre segurança alimentar versus segurança energética, parte desse processo tem sido marcada pela apropriação de riqueza pelo capital internacional ${ }^{8}$. A compra, pelo capital estrangeiro, de unidades de processamento agroindustrial e de vastas propriedades rurais aguarda, ainda, uma melhor regulamentação por parte do governo federal.

Essa expansão das lavouras no Brasil está em sintonia com a expansão mundial de cultivos para os agrocombustíveis (PIETRAFESA et al., 2010; FERNANDES, 2011). De acordo com o Banco Mundial (2010), a área total cultivada com matérias-primas para os agrocombustíveis no mundo em 2008 era estimada em 36 milhões de hectares, duas vezes mais que em 2004. Deste total, 8,3 milhões de hectares estão na União Europeia, com cultivo de canola, 7,5 milhões, nos Estados Unidos, com lavouras de milho, e 6,4 milhões de hectares

\footnotetext{
8 Há vários fundos de investimentos nacionais e internacionais operando no setor sucroalcooleiro, anteriormente concentrados nos chamados fundos de hedge do mercado financeiro, que têm comprado usinas de cana no Brasil (WILKINSON et al., 2011).
} 
Figura 2. Espacialização da produção de cana-de-açúcar no Brasil - 1980 a 2009.
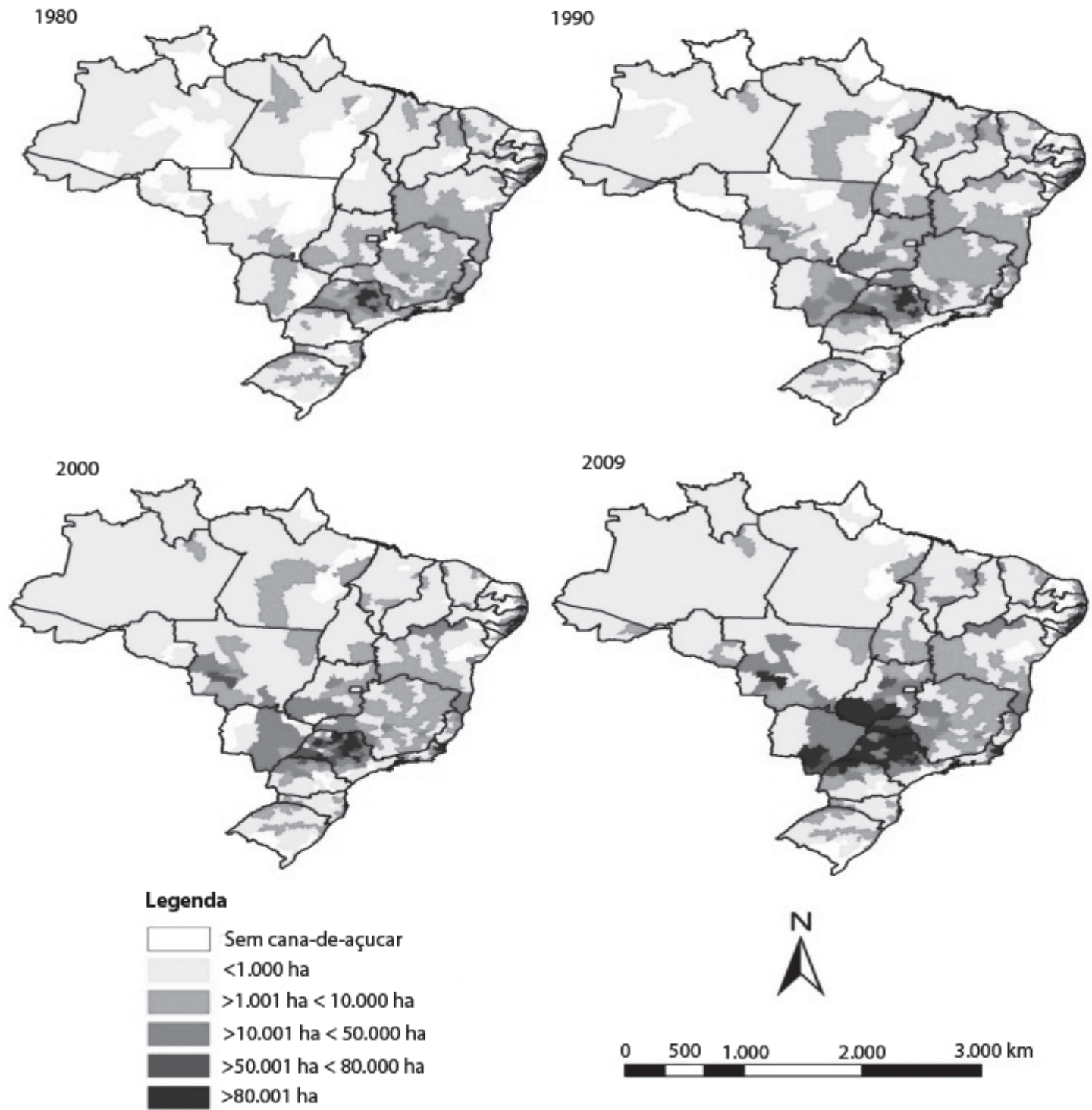

Fonte: IBGE (PAM).

estão na América Latina, basicamente com cultivos de cana no Brasil (BANCO MUNDIAL, 2010).

Com relação aos circuitos de comercialização, no caso da soja e tomando-se como referência os dados disponibilizados pelo IBGE, pode-se verificar que as regiões onde se concentra a maior parte da produção são aquelas onde predominam os processos de comercialização intermediados pela indústria e não por cooperativas ou intermediários, que se concentram, respectivamente nas regiões Sul e Norte do País.
Assim, boa parte da soja produzida nos Cerrados brasileiros (Mato Grosso, em particular) é destinada (além do mercado externo) ao processamento industrial. É possível deduzir que uma parcela dessa produção serve como matéria-prima na fabricação do biodiesel, visto que, das empresas de processamento/produção do óleo já implantadas, fração significativa distribui-se entre os Cerrados do Centro-Oeste, puxado por Mato Grosso. Isso compromete, em parte, a "priorização" geográfica da região do semiárido (qua- 
se $80 \%$ da área territorial do Nordeste brasileiro) como região-alvo do $\mathrm{PNPB}$, malgrado os esforços recentes da empresa Petrobras Biocombustível em concentrar nessa última área suas usinas de processamento (FLEXOR et al., 2010).

Por outro lado, não seria incorreto afirmar que, à frente desse processo de expansão da soja, a agricultura familiar possui um peso residual (LEITE e WEZS, 2010), o que, de certa forma, contradiz as expectativas iniciais de inclusão social esboçadas pelo PNPB ao tentar vincular a produção de oleaginosas (mamona, especialmente) de agricultores familiares instalados no semiárido nordestino à política nacional de produção de biodiesel.

No caso particular da cana-de-açúcar, dados coletados junto ao IBGE informam que a comercialização do produto está fortemente associada à entrega do mesmo junto às usinas e destilarias processadoras, em especial vinculadas à fabricação de açúcar e etanol. Como se trata, em geral, de circuitos curtos de comercialização (diferente da soja, o produto não é exportado in natura), é visível a concentração espacial dos processos de comercialização nas regiões onde está instalada a maior parte das usinas, em especial no estado de São Paulo, como pode ser visto no mapa.

No caso da expansão direcionada à região Centro-Oeste (Goiás e Mato Grosso do Sul), mas também na microrregião de Uberlândia, em Minas Gerais, o aumento do plantio da cana confronta-se com a grande produção de grãos e com a agroindústria do setor de carnes (aves e suínos) previamente estabelecidas nesses locais (LIMA, 2010), resultando em aumento dos preços das terras e no acirramento das disputas territoriais, o que levou alguns municípios dessas regiões a tentar estabelecer um limite de área para o plantio de cana (PIETRAFESA et al., 2010).

Essa expansão espacial das lavouras poderia ser classificada, segundo Wilkinson et al. (2010, p. 32), quanto ao tipo de investidores e motivos do investimento em oitos "categorias":

a) capitais no agro do próprio setor de atividades;

b) capitais no agro de setores sinérgicos e/ou convergentes; c) capitais não tradicionais ao agro que respondem a novas sinergias;

d) empresas de imóveis rurais (corretoras imobiliárias) que têm surgido em resposta à valorização das terras e das perspectivas do agro brasileiro;

e) estados ricos em capital, mas pobres em recursos naturais em busca de assegurar abastecimento alimentar e de energia;

f) fundos de investimento atraídos pelas diversas perspectivas de valorização das commodities agrícolas;

g) investimentos relacionados aos incentivos de serviços ambientais;

h) empresas de mineração e prospecção de petróleo.

É possível inferir ainda que parte desse processo de expansão de culturas valeu-se de investimentos sobre ativos fundiários com origem - direta e/ou indireta - no capital internacional (LEITE e SAUER, 2011; TOULMIN et al., 2011). Tal estratégia reforça a ideia, já registrada por Wilkinson et al. (2010), que os grupos internacionais (sejam empresas, pessoas físicas ou governos) vêm direcionando seus recursos no setor agropecuário não apenas nas atividades de processamento de matéria-prima, como era usual, mas particularmente na arrecadação de imóveis rurais propriamente ditos (como é o caso dos projetos conhecidos como greenfields), como veremos a seguir (TOULMIN et al., 2011; COTULA, 2012; SAFRANSKY e WOLFORD, 2011).

\section{A estrangeirização da propriedade fundiária no Brasil}

Estudos encomendados pelo Núcleo de Estudos Agrários e Desenvolvimento Rural (Nead) do Ministério do Desenvolvimento Agrário (MDA), mostram que houve um crescimento significativo de investimentos estrangeiros diretos (IEDs) totais no Brasil a partir de 2002 (107\% entre 2002 e 2008, passando de 4,33 a 8,98 bilhões de dólares no mesmo período). Segundo o jornal O Globo, o Instituto de Pesquisa Econômica Aplicada (Ipea) mos- 
trou que os IEDs no setor primário brasileiro passaram de US\$ 2,4 bilhões, em 2000, para US\$ 13,1 bilhões, em 2007 , sendo que a alta de $445 \%$ foi puxada pela mineração, que respondeu por $71 \%$ do total recebido nesse último ano (ALVIM, 2009).

Seguindo a tendência de aumento desses investimentos estrangeiros no Brasil nos últimos anos, houve crescimento da participação externa nas atividades agropecuárias ${ }^{9}$ como, por exemplo, no cultivo da cana-de-açúcar e da soja e na produção de álcool e agrocombustíveis (ALVIM, 2009, p. 53). Uma parte significativa destes investimentos foi utilizada para compra e fusões de empresas já existentes (ALVIM, 2009), sendo que "o total de IED realizado no agronegócio foi de 46,95 bilhões de dólares" (p. 52), entre 2002 e 2008 (ALVIM, 2009, p. 47). Segundo Alvim (2009),

[...] a produção industrial de biocombustíveis foi a atividade que apresentou uma tendência clara de crescimento na captação de investimentos estrangeiros no Brasil, sendo esta concentrada preponderantemente nos estados do Sudeste. Os IEDs em álcool e biocombustíveis passaram de 4 milhões de dólares em 2002 para 1,64 bilhões de dólares em 2008 (p. 55).

Utilizando diferentes fontes de informações, como empresas de consultoria no ramo, entre outras, os jornais de circulação nacional vêm publicando dados sobre este processo de aquisição de terras por estrangeiros no Brasil, ${ }^{10}$ sem a "devida correspondência nos registros do SNCR/ Incra" (PRETTO, 2009, p. 4).

9 Até 2000, o setor primário participava com apenas 2,3\% do total dos recursos estrangeiros investidos no Brasil, sendo que, em 2007 , chegou a quase $14 \%$, enquanto a expansão dos investimentos estrangeiros no setor industrial foi de 33,4\% no mesmo período (DUARTE, 2008).

10 Já em meados dos anos 2000, os principais jornais brasileiros publicavam reportagens sobre o processo de "estrangeirização" das terras no Brasil (SCOLESE, 2008; CHADE, 2010). A Folha, divulgando dados sobre o avanço do capital estrangeiro, afirmou que "empresas e pessoas de outros países compram o equivalente a 22 campos de futebol em terras no Brasil a cada uma hora. Em dois anos e meio, os estrangeiros adquiriram 1.152 imóveis, num total de 515,1 mil hectares" (ODILLA, 2010).
A partir de dados do SNCR, a Folha de S. Paulo, por exemplo, calculou este ritmo de "estrangeirização" de terras em um intervalo de apenas seis meses. Segundo dados da Folha, entre novembro de 2007 e maio de 2008, estrangeiros adquiriram em torno de 1.533 imóveis rurais no Brasil, abarcando uma área de 226.920 hectares. No mesmo período, houve também transações de venda de imóveis, mas o saldo foi de 1.372 imóveis adquiridos por pessoas de outras nacionalidades, totalizando 205.320 hectares (SCOLESE, 2008, p. A10).

Apesar de não existir um levantamento mais sistemático em termos nacionais, é possível concluir que esses investimentos estrangeiros no setor primário brasileiro resultam também na aquisição de muitas terras (LEITE e SAUER, 2011; TOULMIN et al., 2011). De acordo com levantamento realizado pelos estudos do Nead, no SNCR do Incra, existiam 34.632 registros de imóveis em mãos de estrangeiros em 2008, que abarcavam área total de 4.037.667 hectares, números bastante expressivos considerando-se que não abrangeu o "período da corrida por terras" após a crise de 2008 (PRETTO, 2009). Deve-se ressaltar que mais de $83 \%$ desse total são imóveis classificados como grandes propriedades (acima de 15 módulos fiscais).

A Tabela 2, extraída do estudo de Pretto (2009, p. 21), ilustra bem o processo de aquisição de imóveis rurais por estrangeiros, demonstrando o crescimento histórico no número de imóveis e na quantidade de terras registradas por pessoas e empresas estrangeiras. Apesar da queda de registros a partir dos anos 1990, conforme já mencionado, as décadas de 1980, 1990 e 2000 concentram esse movimento, respondendo, respectivamente, por $29,9 \%, 18,2 \%$ e $18,8 \%$ do número total de imóveis sob registro de estrangeiros, e por $27,9 \%$, $25,9 \%$ e $20,1 \%$ da área total cadastrada.

Esse processo de estrangeirização de terras brasileiras não é recente (OLIVEIRA, 2010). Marco importante nesse percurso histórico foi a cooperação nipo-brasileira na implementação das distintas fases do Programa de Cooperação Nipo-Brasileiro para o Desenvolvimento dos Cerrados (Proceder), idealizado em meados dos anos 1970 e implantado ao longo das décadas de 1970 e 1980 em diversas re- 
Tabela 2. Percentual de aquisição (no de imóveis e área) de terras por estrangeiros no Brasil (1900-2000).

\begin{tabular}{ccccc}
\hline \multicolumn{5}{c}{ Brasil - Participação relativa de registros e áreas por décadas } \\
\hline Décadas & \% Registros & \% Acumulado dos registros & \% Áreas & \% Acumulado de área \\
\hline 1900 & 0.012 & 0.012 & 0.0004 & 0.0004 \\
1910 & 0.047 & 0.058 & 0.064 & 0.065 \\
1920 & 0.143 & 0.202 & 0.170 & 0.235 \\
1930 & 0.415 & 0.617 & 0.309 & 0.544 \\
1940 & 1.207 & 1.824 & 0.971 & 1.514 \\
1950 & 4.015 & 5.839 & 2.551 & 4.065 \\
1960 & 8.773 & 14.612 & 6.194 & 10.259 \\
1970 & 17.421 & 32.033 & 15.040 & 25.298 \\
1980 & 29.888 & 61.921 & 27.940 & 53.238 \\
1990 & 18.201 & 80.122 & 25.925 & 79.163 \\
2000 & 18.783 & 98.904 & 20.152 & 99.315 \\
Totais & 1.096 & 100.000 & 0.685 & 100.000 \\
\hline
\end{tabular}

Fonte: SNCR/Incra Apuração Especial 2008 (apud PRETTO, 2009, p. 21).

giões do Cerrado brasileiro, especialmente nos estados de Minas Gerais, Goiás, Bahia e Mato Grosso (BERTRAND et al., 1991; SALIM, 1986).

Uma atualização dos dados para 2010, valendo-nos da mesma base cadastral elaborada pelo Incra, indica, como pode ser visto na Tabela 3, a existência de 34.371 imóveis rurais sob a propriedade de estrangeiros, abarcando um total de 4.349.074 hectares. Pela mesma tabela é possível observar que a maior parte do número de imóveis está concentrada nos estados de São Paulo (35,7\% do total), Paraná $(14,9 \%)$, Minas Gerais $(7,68 \%)$ e Bahia (6,38\%). Quando tomamos o total de área o quadro se altera, apontando a liderança para os estados de Mato Grosso (19,4\% da área total), Minas Gerais e São Paulo (com 11,3\% cada) e Mato Grosso do Sul (10,9\%). Em ambos os casos, coincidindo significativamente com a expansão das fronteiras agrícolas.

Nosso acesso à base de dados não permitiu identificar a data de aquisição/acesso a esses imóveis, dificultando uma precisão maior sobre o movimento de estrangeirização nos últimos anos. No entanto, levando-se em conta as informações do Banco Mundial, já comentadas anteriormente, há uma intensificação desse fluxo de inversões a partir de 2008. Assim, tomando-se os dados anteriormente apresentados por Pretto (2009), re- lativos à posição do cadastro em 2008, pudemos estabelecer uma comparação aproximativa para verificar a variação (absoluta e relativa) estabelecida ao longo de quase dois anos (2008-2010).

É possível constatar um aumento no número de imóveis (acréscimo de 153 registros, representando elevação de $0,45 \%$ em relação ao dado de 2008), mas, sobretudo, um incremento significativo na quantidade de terra incorporada por estrangeiros: aproximadamente 312 mil hectares, representando alta de cerca de $8 \%$ em relação à base anterior, em um escasso intervalo de tempo, visto que nossos dados são referentes apenas a maio de 2010.

As maiores variações positivas no número de imóveis entre 2008 e meados de 2010 foram registradas nos estados de Minas Gerais (14,24\%), Roraima (13,79\%) e Rio Grande do Norte $(12,28 \%)$. Quando tomamos a quantidade de terra incorporada, vemos que o quadro altera-se bastante, indicando os estados do Amazonas (com forte aumento de $120 \%$ na quantidade de área registrada), do Piauí (com 77,7\%), de Minas Gerais (com $57,4 \%$ ), e do Espírito Santo (com 43,9\%) como aqueles com maior expressão. Parte desse movimento, pode-se especular, deve estar atrelada à expansão das atividades agropecuárias e agroindustriais, tanto no setor de grãos e de cana-de-açúcar quanto nos setores florestal e mineração. 
Tabela 3. Número e área de imóveis rurais sob a propriedade de estrangeiros (Brasil - maio de 2010).

\begin{tabular}{|c|c|c|c|c|}
\hline Estados & N. de Imóveis & $\%$ & Área (ha) & $\%$ \\
\hline Rondônia & 119 & 0,35 & $29.242,00$ & 0,67 \\
\hline Acre & 26 & 0,08 & $13.799,68$ & 0,32 \\
\hline Amazonas & 307 & 0,89 & $232.021,68$ & 5,33 \\
\hline Roraima & 66 & 0,19 & $27.729,49$ & 0,64 \\
\hline Pará & 1.143 & 3,33 & $235.628,39$ & 5,42 \\
\hline Amapá & 15 & 0,04 & $6.228,00$ & 0,14 \\
\hline Tocantins & 181 & 0,53 & $109.517,18$ & 2,52 \\
\hline Maranhão & 184 & 0,54 & $70.135,35$ & 1,61 \\
\hline Piauí & 82 & 0,24 & $58.770,32$ & 1,35 \\
\hline Ceará & 401 & 1,17 & $34.734,45$ & 0,80 \\
\hline Rio Gde Norte & 128 & 0,37 & $20.806,69$ & 0,48 \\
\hline Paraíba & 248 & 0,72 & $6.828,47$ & 0,16 \\
\hline Pernambuco & 368 & 1,07 & $9.667,19$ & 0,22 \\
\hline Alagoas & 101 & 0,29 & $13.577,66$ & 0,31 \\
\hline Sergipe & 81 & 0,24 & $3.439,45$ & 0,08 \\
\hline Bahia & 2.192 & 6,38 & $368.888,05$ & 8,48 \\
\hline Minas Gerais & 2.639 & 7,68 & $491.548,57$ & 11,30 \\
\hline Espírito Santo & 304 & 0,88 & $19.770,66$ & 0,45 \\
\hline Rio de Janeiro & 2.110 & 6,14 & $85.284,78$ & 1,96 \\
\hline São Paulo & 12.291 & 35,76 & $491.437,42$ & 11,30 \\
\hline Paraná & 5.130 & 14,93 & $299.061,84$ & 6,88 \\
\hline Santa Catarina & 1.290 & 3,75 & $54.605,77$ & 1,26 \\
\hline Rio Gde Sul & 1.895 & 5,51 & $113.801,07$ & 2,62 \\
\hline Mato Grosso Sul & 781 & 2,27 & $473.325,65$ & 10,88 \\
\hline Mato Grosso & 1.229 & 3,58 & $844.279,92$ & 19,41 \\
\hline Goiás & 843 & 2,45 & $230.629,91$ & 5,30 \\
\hline Distrito Federal & 217 & 0,63 & $4.314,36$ & 0,10 \\
\hline Total Brasil & 34.371 & 100,00 & $4.349 .074,00$ & 100,00 \\
\hline
\end{tabular}

Fonte: Incra. Posição em maio de 2010. Dados ajustados pelos autores.

Tabela 4. Origem do capital aplicado em terras no Brasil (2010).

\begin{tabular}{lccc}
\hline \multicolumn{1}{c}{ País } & Área (em ha) & $\%$ & $\%^{*}$ \\
\hline Portugal & $1.030 .119,42$ & 23,68 & 36,95 \\
Japão & $432.469,84$ & 9,94 & 15,51 \\
Itália & $256.145,06$ & 5,89 & 9,19 \\
Líbano & $172.696,63$ & 3,97 & 6,19 \\
Espanha & $127.499,12$ & 2,93 & 4,57 \\
Alemanha & $123.667,19$ & 2,84 & 4,44 \\
Holanda & $114.189,29$ & 2,62 & 4,10 \\
Subtotal & $2.787 .713,56$ & & \\
Outros & $530.927,01$ & 12,21 &.-- \\
Inf. Inexistente & $1.208 .690,22$ & 27,79 &.-- \\
Inf. Inválida & $352.598,26$ & 8,11 &.-- \\
Total & $4.349 .002,04$ & 100,00 & \\
${ }^{*}$ Obs.: Esses percentuais excluem as áreas classificadas como inválidos ou inexistentes. & \\
Fonte: Incra. Posição maio 2010. Dados ajustados pelos autores. & &
\end{tabular}


O manuseio dessas informações estatísticas exige certa cautela nas conclusões, como atestam os dados referentes à origem do capital aplicado em ativos fundiários (nos registros do Incra, cerca de $35 \%$ das informações relativas a esse item apresentavam dados inexistentes ou inválidos). Apesar disso, é possível extrair algumas considerações sobre os países de origem dos fluxos de inversões em terras.

A Tabela 4 contém todos os registros, incluindo aqueles cuja informação da origem é inexistente ou inválida. Pela mesma observamos que os sete principais países com participação no total de terras inscritas no cadastro são: Portugal, Japão, Itália, Líbano, Espanha, Alemanha e Holanda. Isso fica mais evidente quando descartamos da base os registros problemáticos e extraímos a participação desses países sobre o total de terras de todos os países computados (conforme é possível observar na última coluna da Tabela 4). Como a referência temporal da tabela inclui registros desde o início do século passado, é evidente que o quadro informa uma presença expressiva de países com forte participação nos processos de colonização e imigração atestados pelo Brasil ${ }^{11}$.

Não dispomos de informações mais detalhadas que permitiriam cruzar a origem do capital com a data de aquisição, o tamanho do imóvel e sua localização geográfica. No entanto, praticamente $3 / 4$ de todos os registros imobiliários referem-se à posse e/ou propriedade de pessoas físicas, e o restante $(26 \%)$, a pessoas jurídicas. Como chamam a atenção Wilkinson et al. (2010), nesse último caso, a identificação do capital estrangeiro é mais complicada, pois vários investidores valem-se de empresas nacionais para apropriação dessas áreas.

11 Diferente das constantes notícias veiculadas pela grande imprensa (MAISONNAVE, 2011), alguns paísesnão aparecem entre os detentores de terras no Brasil, sendo a China o exemplo mais notório e recorrente. Entre outros motivos para tais omissões, devemos considerar que os dados do SNCR não abarcam as aquisições e transações de terras mais recentes.

\section{Mercado de terras e a flutuação do preço dos imóveis}

Outro aspecto que nos parece fundamental discutir aqui é o impacto desse movimento de expansão do agronegócio e estrangeirização da propriedade fundiária sobre o mercado de terras e a flutuação de seus preços (BORRAS et al., 2011; TOULMIN et al., 2011). Os projetos sucroalcooleiros implantados entre 2008 e 2010 provocaram a valorização das terras nas regiões de expansão dos cultivos de cana-de-açúcar, especialmente nas novas "fronteiras", localizadas principalmente nos estados de Goiás, Mato Grosso do Sul e Minas Gerais (BATISTA, 2010; FERNANDES, 2011). Segundo estudo feito pela NAI Commercial Properties, multinacional americana especializada no mercado imobiliário, os preços das terras tiveram forte alta desde 2009, com aumentos de até 33\% no município de Pedro Afonso (TO). Segundo O Valor Econômico,
Algumas regiões de Goiás também regis- traram uma das maiores valorizações puxadas pela cana. Estudo de mercado feito pela NAI na região do município de Edeia identificou que o hectare, que valia R\$ 8,5 mil em 2009, está sendo negociado agora no mercado a $\mathrm{R} \$ 10$ mil, aumento de $17 \%$. É no município de Edea que está o projeto da usina Tropical, sociedade entre a petroleira British Petroleum, com o grupo Maeda - agora vendido ao fundo Arion Capital - e da Santelisa Vale, agora controlada pela francesa Louis Dreyfus (BATISTA, 2010, p. B12).

Esse aumento nos preços impacta sobre outras políticas (além da política agrícola de incentivos ao setor), mas especialmente sobre as políticas agrárias (LEITE e SAUER, 2011). Além de acirrar as disputas territoriais, as políticas fundiárias são prejudicadas porque, entre outros fatores, fica mais caro desapropriar e indenizar os imóveis para fins de reforma agrária, por meio da implantação de assentamentos (ADAMS, 2010, p. 2). 
Por outro lado, é fundamental ter presente que parte significativa dos investimentos estrangeiros é financiada com recursos públicos (SAUER, 2010a; SAFRANSKY e WOLFORD, 2011 ${ }^{12}$, especialmente recursos do Banco Nacional de Desenvolvimento Econômico e Social (BNDES) e do Fundo Constitucional do Centro-Oeste (FCO). Estes empréstimos e incentivos fiscais estão sendo alocados principalmente em região de expansão do cultivo de cana e produção de etanol (Centro-Oeste) e soja (Centro-Oeste, Amazônia, Bahia e Tocantins) (PIETRAFESA et al., 2010).

O BNDES é o maior fornecedor de crédito para o setor sucroalcooleiro para a produção de etanol. Nos anos de 2007 e 2008, o banco financiou mais de 50 projetos do setor, sendo que boa parte desses financiamentos foi destinada à compra de equipamentos (geração de energia elétrica a partir do bagaço) e à ampliação do parque industrial, especialmente nas regiões de expansão da cana, como Mato Grosso do Sul e Goiás (PIETRAFESA et al., 2010). Em outras palavras, recursos públicos ajudam a manter o mercado de terras aquecido, viabilizando inclusive investimentos estrangeiros na produção de commodities agrícolas.

No Brasil, o investimento em terra representou, por um bom período de tempo, uma alternativa sólida para inversões de capitais (BRANDÃO, 1988), seja com o intuito de valorizá-lo diretamente ${ }^{13}$ (em um tipo de investimento que, apesar de não atestar os maiores picos de rendimentos, não oferecia risco à desvalorização da aplicação), seja com o objetivo de, por meio da terra, acessar a

12 Segundo Safransky e Wolford (2011, p. 5), "corredores extensos de infraestrutura vêm sendo construídos em todo o Continente" latino-americano com recursos públicos, promovidos pelos Estados e pelos organismos multilaterais de financiamento, "para ligar fronteiras extrativas às áreas metropolitanase aos mercados estrangeiros" atraindo investimentos privados e criando "tendências para o land grabbing nas Américas".

13 Ignácio Rangel cunhou a ideia de uma quarta renda da terra (em complementação às rendas absolutas, diferenciais I e II), com base na forte valorização financeira dos imóveis rurais no Brasil, apontando pioneiramente a capacidade da propriedade fundiária em constituir-se em algo próximo a um ativo financeiro, trazendo para si capitais que fugiam da desindexação da moeda corrente, em especial durante a crise econômica da década de 1980 (RANGEL, 1986). política de crédito rural dos anos 1960 e 1970, fortemente subsidiada (DELGADO, 2005).

Para uma breve retrospectiva histórica sobre o comportamento dos preços de compra e venda dos imóveis rurais, Wilkinson et al. (2010, p. 70) apresentam uma periodização que informa um arrefecimento do mercado após o processo de estabilização macroeconômica no Brasil, com a adoção do Plano Real em 1994, após décadas de combate inflacionário. Assim, em meados dos anos 1990, o mercado atesta um refluxo nos preços dos imóveis rurais, o que instigou o ministro da área agrária à época a afirmar que a "estrutura do latifúndio no Brasil está finalmente quebrada". Porém, como bem argumenta Wilkinson et al. (2010), já no início dos anos 2000 os preços recuperam-se rapidamente, associados ao bom desempenho dos preços das principais commodities, com a soja em primeiro lugar até 2004.

Seguiu-se então um curto período de estabilidade no preço das áreas com lavouras, que voltaram a avançar expressivamente a partir de 20072008; segundo os autores, essa elevaçãolastreia-se nos investimentos realizados na produção de etanol. Com a crise financeira de 2008, há um impacto momentaneamente negativo no comportamento dos preços, mas não atinge as regiões mais estratégicas para a produção de commodities, como veremos a seguir (LEITE e WESZ, 2010).

Assim, é possível afirmar que, de modo geral, o processo de expansão das áreas produtivas baseadas em monoculturas direcionadas à exportação, examinado até aqui, rebateu, adicionalmente, em um aumento recente no preço dos imóveis rurais localizados nessas regióes (LEITE e WESZ, 2010). Primeiramente é necessário observar que, após o final da década de 1990, o preço das terras com lavouras dispara significativamente, em termos médios para o caso brasileiro, como podemos constatar na Figura 3, que apresenta dados para o total do Paíse para alguns estados selecionados (São Paulo, Pará e Mato Grosso).

É possível verificar que o valor médio por hectare das áreas com lavoura, no caso brasileiro, salta, em termos nominais, de $\mathrm{R} \$ 1.188,30 \mathrm{em}$ junho de 1994 para $R \$ 7.490,40$ em junho de 2010 
Figura 3. Variação nos preços de vendas das terras de lavoura (R\$/ha) no Brasil e estados selecionados 1994/2010 - valores constantes a preços de agosto de 1994.

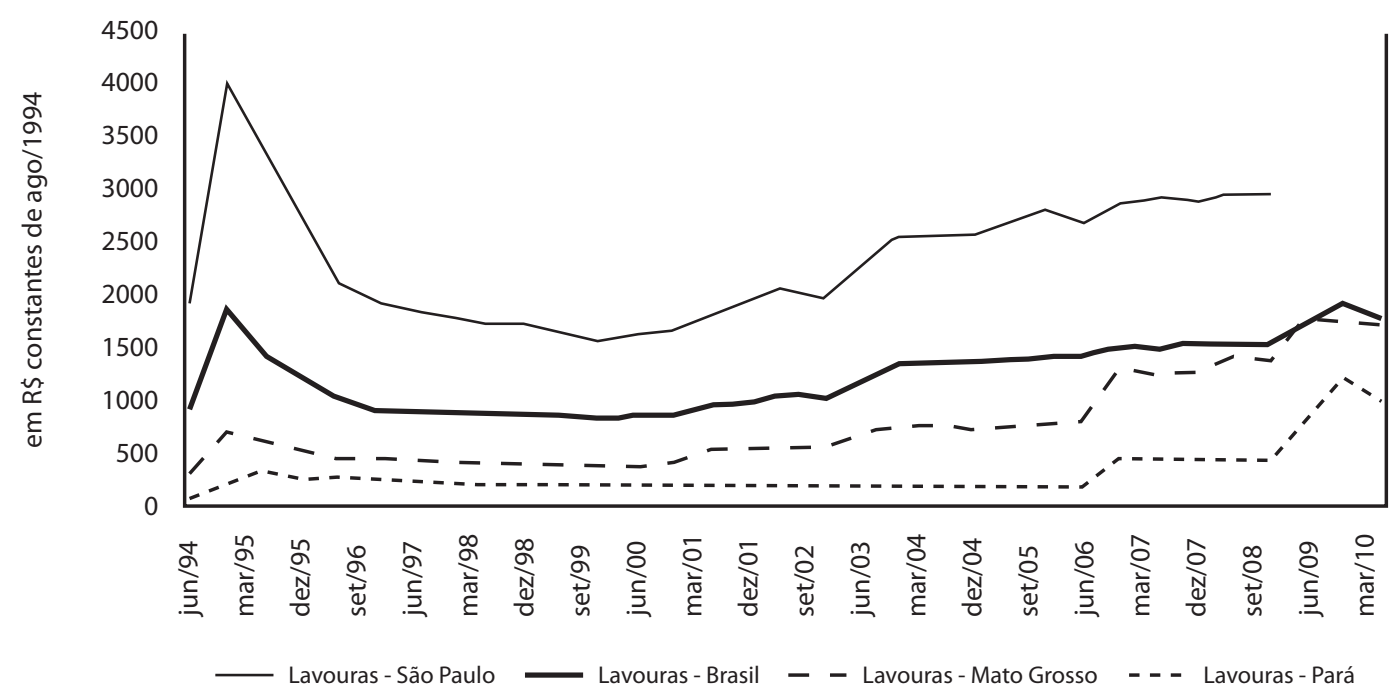

Fonte: Fundação Getúlio Vargas/FGVDados. Valores nominais deflacionados pelo IGP-DI.

(aumento de mais de 430\%). Quando tomamos os valores constantes, o aumento é de $93,3 \%$, o que, mesmo assim, representa incremento importante na variação de preços. A intensidade desse aumento se dá a partir de 2000 (após o pico observado no momento da implantação do Plano Real em 1994, como bem observou Rezende, 2003), movimento que é acompanhado pelo estado de Mato Grosso (forte produtor de grãos) e pelo Pará, cuja valorização das terras é mais recente, visto que o processo de ocupação das áreas se deu ao longo da década de 2000. É digna de nota a forte valorização das lavouras paulistas, área que, como vimos, concentra a expansão de cana-de-açúcar e o valor médio mais elevado quando comparado à média nacional ( R\$ 12.020,00/ha contra R\$ 6.283,00/ha, para dezembro de 2008, em valores nominais).

Esse movimento fica ainda mais evidente em algumas regiões que são objeto de expansão das commodities, em particular a área compreendida como Cerrado brasileiro. Tomaremos como exemplo novamente o caso mato-grossense. Além das fortes variações observadas no preço de compra e venda das áreas com lavouras, observamos igualmente um acréscimo considerável nos preços das áreas com pastagens, que se transformam, na sequência, em novas áreas abertas para o cultivo de soja e algodão (LEITE e WESZ, 2010).

Além de Mato Grosso, em algumas outras regiões, como os Cerrados existentes nos estados de Minas Gerais, Goiás e Bahia, a forte valorização das terras tem sido estimulada também pela entrada maciça de novos investimentos na produção de cana-de-açúcar, especialmente em Minas e Goiás, voltados à fabricação de etanol, no bojo da emergência dos novos combustíveis à base de recursos naturais. Isso pode ser verificado nas Figuras 4 e 5, construídas a partir dos dados coletados junto ao Instituto $\mathrm{FNP}^{14}$.

Na região do oeste baiano, também conhecida pelos chapadões que observaram a entrada da soja ao longo dos anos 1980 e 1990, e atualmente

${ }^{14}$ Diferente da Fundação Getúlio Vargas (FGV), que não disponibiliza dados sobre o mercado de terras para municípios e regiões específicas (especializando-se nas informações semestrais sobre o comportamento agregado, segundo tipo de terra), por estado e para toda a Federação, o Instituto FNP coleta e sistematiza bimestralmente o comportamento dos preços para diferentes situações de imóveis nas 133 regiões definidas pela pesquisa. No entanto, a recuperação dos dados para esta fonte limita-se, no nosso caso, a 2002, enquanto que para os dados da FGV há uma série histórica bem mais ampla. 
Figura 4. Variação nos preços das terras (R\$/ha) da Bahia - oeste baiano - 2002/2010 - valores constantes a preços de agosto de 1994 (municípios selecionados).

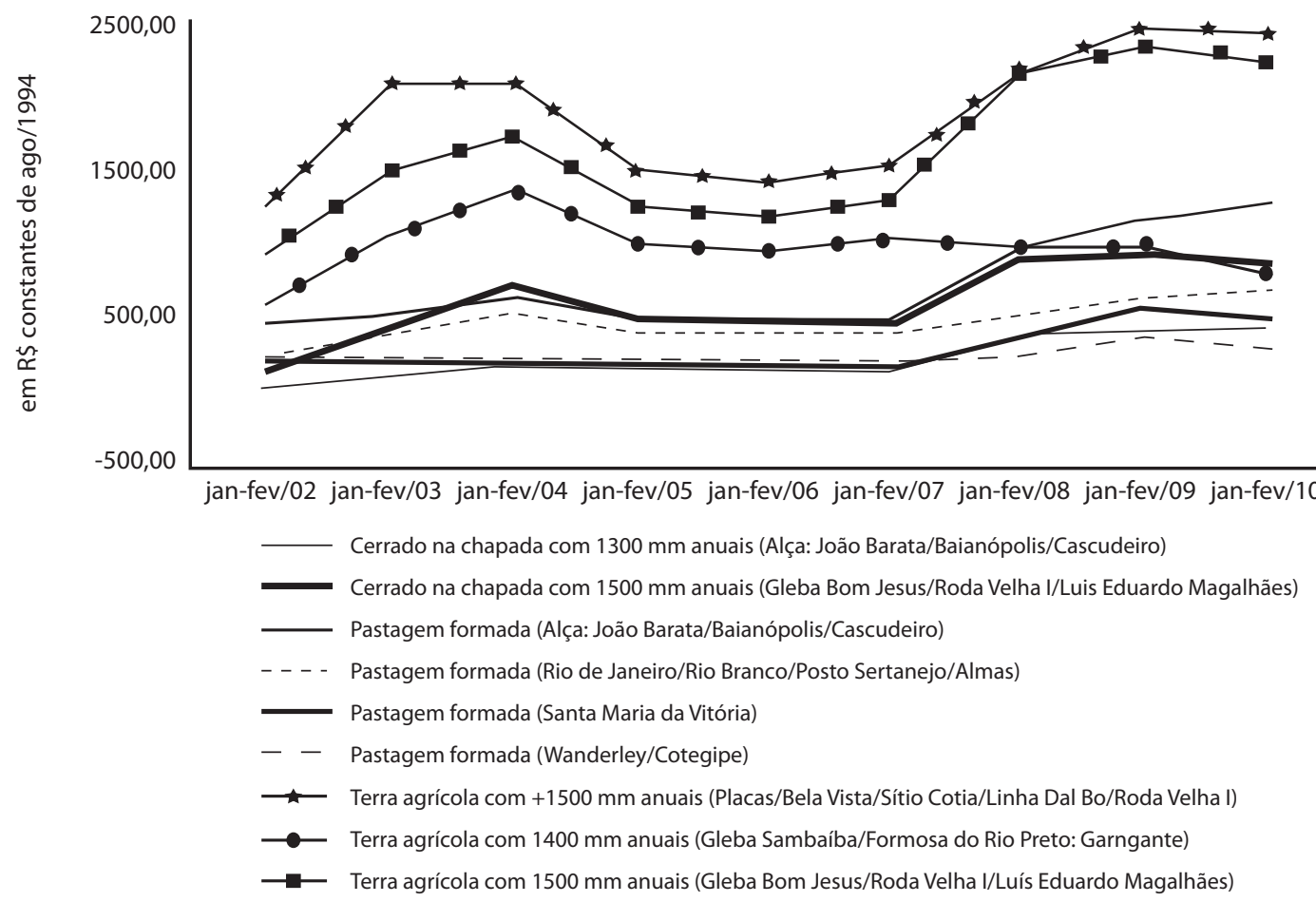

Fonte: Instituto FNP.

Figura 5. Variação nos preços das terras (R\$/ha) de Mato Grosso - região de Sinop - 2002/2010 - valores constantes em preços de agosto de 1994 (municípios selecionados).

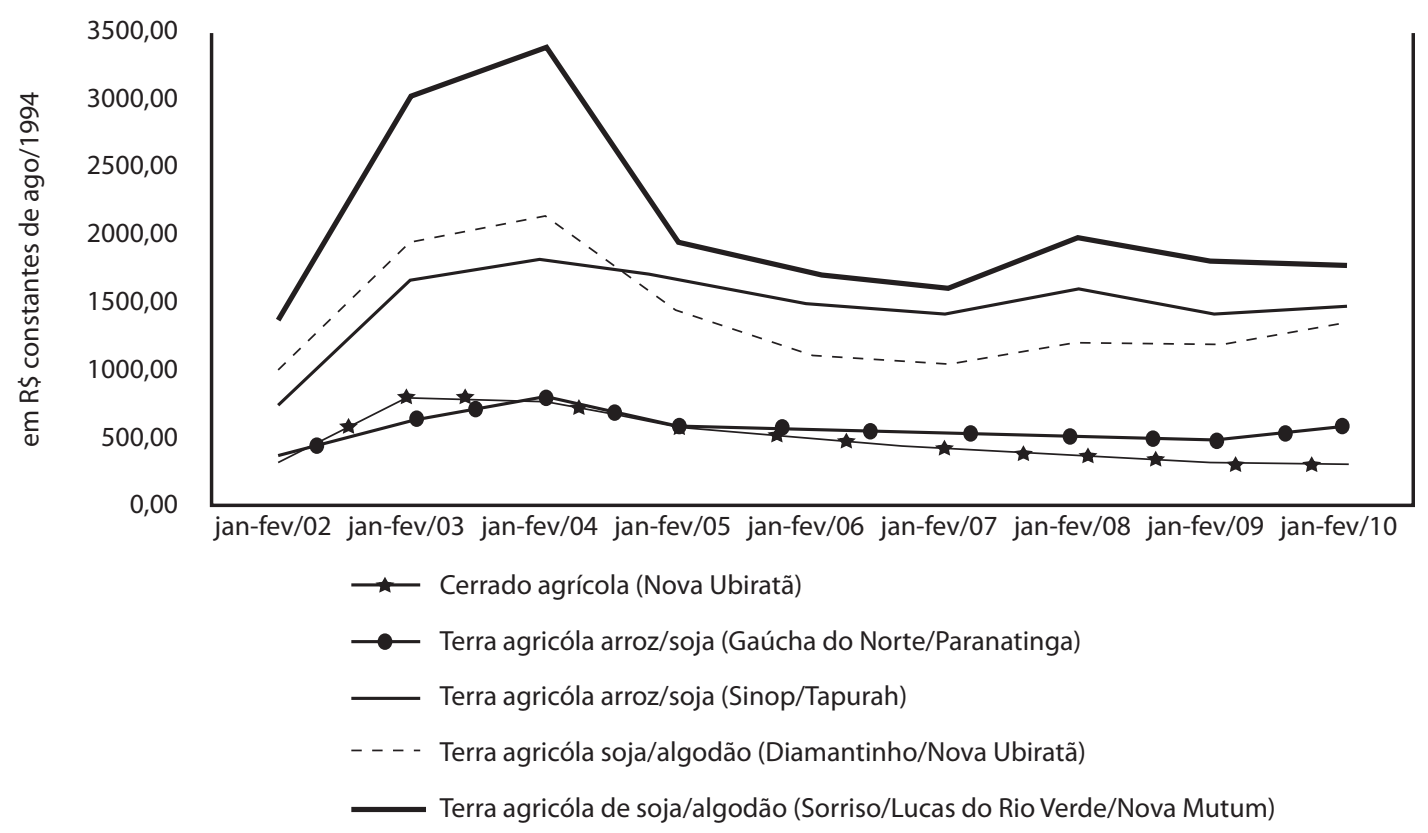

Fonte: Instituto FNP. 
abrigam ainda a expansão da produção de algodão e cana (capitais nacionais e internacionais), as variações de preços são também importantes. Com efeito, após o recuo de 2005-2006, os valores recuperaram-se velozmente, em particular nas terras agrícolas do município de Luis Eduardo Magalhães e arredores. Apesar do ligeiro decréscimo apresentado em 2010, o município citado assistiu um aumento da cotação dos imóveis rurais, em termos nominais, de $\mathrm{R} \$ 2.000,00 / \mathrm{ha}$ em janeiro de 2002 para $\mathrm{R} \$ 9.000,00 /$ ha em janeiro de 2010, após ter atingido R \$9.500,00/ha em janeiro de 2009. Em valores constantes comparáveis ao gráfico anterior, como consta na Figura 4, isso representou, em média, aumento real de $164 \%$ (excluindo-se as variações extremas), considerados os diferentes tipos de terra objeto de acompanhamento.

Tomamos ainda, por meio da Figura 5, o caso do meio-norte mato-grossense, objeto de forte expansão da área cultivada com grãos, como vimos anteriormente. Dado o atrelamento dos preços dos imóveis ao comportamento do mercado internacional de commodities (especialmente a soja), é evidente o refluxo observado no interregno 2004-2007, após fortíssima elevação. Depois de 2007 , as terras objeto de plantio de soja e algodão (envolvendo os municípios de Lucas do Rio Verde e Nova Ubiratã, entre outros) são novamente valorizadas, atestando cotações que variam entre R\$ 5.500,00/ha a R \$ 7.200,00/ha (em valores nominais), em janeiro de 2010. Quando comparamos, em valores constantes, o período inicial com o momento final constante no gráfico, verificamos uma variação real média (considerados os diferentes tipos de terra)de 43,6\% em apenas oito anos.

Parece-nos evidente, dessa forma, que a expansão das atividades do agronegócio nas fronteiras agrícolas, associadas ao incremento de investimentos estrangeiros, tiveram como resultado um forte processo de valorização dos preços das terras. Esse incremento compromete a situação de diversos segmentos que, diante desse quadro, viram-se forçados a realizar deslocamentos em direção a áreas mais distantes, tornando a questão do acesso à terra e ao território bem mais complexa.

\section{Demanda por terras: limites governamentais e lutas sociais}

A partir da constatação de que "a demanda por terra tem sido enorme" (BANCO MUNDIAL, 2010, p. vi) e de que "é improvável que a 'corrida por terra' desacelere" (BANCO MUNDIAL, 2010, p. 9), o Banco Mundial (Bird) fez uma série de recomendações. Como o Bird entende essa demanda como uma "oportunidade de negócios", a sua preocupação central é dar sustentabilidade a essa oportunidade, promovendo investimentos de forma "responsável" (BANCO MUNDIAL, 2010), o que valeria também para o caso brasileiro.

Analisando o documento do Banco Mundial, Nassar (2010) corrobora as conclusões do mesmo, salientando essa demanda crescente como uma importante "janela de oportunidades" também para o Brasil. Usando os exemplos dos setores de comunicação e financeiro, Nassar também defende mecanismos de regulação para garantir que o investidor estrangeiro preste serviços no País ${ }^{15}$. Segundo ele,

Da mesma forma, podem ser criadas medidas que obriguem o investidor em terra a gerar renda e emprego, não concentrar a posse da terra, cumprir, acima da média do setor, suas obrigações ambientais e promover transferência de tecnologia para produtores menos preparados. Com incentivos corretos, o investidor estrangeiro pode se transformar em exemplo para o setor agrícola (NASSAR, 2010).

\footnotetext{
15 Analisando as diversas propostas de "código de condutas" para a aquisição de terras, elaboradas pelo IFPRI e Banco Mundial, entre outros, Borras e Franco (2010, p. 14) apontam uma série de perigos, concluindo que aquelas são baseadas na "creencia, desproveída de toda mirada crítica, enlabenevolencia fundamental de medidas de carácter formal y jurídico, como contractos más claros, derechos de propiedad más claros y seguros (entendidos, por lo general, como derechos privados e individuales), contractos transparentes, laexistencia de um consentimiento libre, prévio e informado, y elestablecimiento de partenariados entre el Estado y la sociedad civil".
} 
Nessa mesma perspectiva, o editorial do jornal O Estado de S. Paulo (2010), sob o título "China compra terras no Brasil" afirmou:

O ex-ministro Antônio Delfim Netto tem razão quando recomenda cuidado com as vendas de terras a empresas da China, controladas pelo Estado ou com participação estatal. Investimentos estrangeiros são de modo geral bem-vindos e podem trazer contribuições importantes ao crescimento do País. Grupos estrangeiros podem fazer bons negócios e ao mesmo tempo fortalecer a economia brasileira com recursos adicionais e, ocasionalmente, com aporte de tecnologia. Mas os 'negócios' mudam de sentido quando o investimento é subordinado a razões estratégicas de um Estado estrangeiro. No caso de recursos naturais, e de terras para a agropecuária, avaliar corretamente essa estratégia é uma questão de segurança (p. A3).

Apesar de certo consenso de que é necessária alguma cautela diante da voracidade dos investimentos estrangeiros, não há qualquer acordo sobre medidas concretas a serem adotadas. Mesmo expressando sobressaltos diante de tal voracidade, as posições vão de uma constante defesa da livre circulação de capital (incluindo a compra de terras), passando por proposições de criação de instituições e regras visando restringir a transferência de ganhos para o exterior (NASSAR, 2010), até demandas de maior controle pelo Estado (ALFONSIN, 2010).

As lutas históricas pela desconcentração da propriedade fundiária levaramas entidades e movimentos sociais do Fórum Nacional pela Reforma Agrária a promover, em 2010, uma campanha nacional pelo limite da terra no Brasil. A campanha, composta por um plebiscito (consulta à população) e um abaixo-assinado (apoio a uma lei sobre o assunto), tinha como objetivo estabelecer o limite máximo de 35 módulos fiscais para toda e qualquer propriedade, e não apenas para estrangeiros.
Segundo material da campanha, o estabelecimento de um limite máximo teria dois pontos centrais, os quais não ameaçam a propriedade privada, mas possibilitam diminuir o nível de concentração fundiária. Estes aspectos seriam: a) estabelecer um mecanismo claro de uso limitado de um bem comum (a terra); b) estabelecer a justiça no campo, pois todos devem ter direito à terra e os demais direitos, que são assegurados a partir do acesso à terra.

O Executivo Federal brasileiro, a partir da preocupação com uma possível perda de soberania territorial e de posições do Incra, solicitou que a AGU fizesse uma revisão do Parecer GQ n. 181. Isso porque este parecer, publicado em 1998, desmobilizou "qualquer forma de controle efetivo sobre a aquisição de terras por parte de empresas estrangeiras no Brasil" (PRETTO, 2009, p. 7) ${ }^{16}$.

Esta perda de controle é explicitamente reconhecida no novo parecer da AGU, publicado em 2010. De acordo com os termos do referido documento, desde os pareceres anteriores, os de 1994 e de 1998,

[...] o Estado brasileiro perdera as condições objetivas de proceder a controle efetivo sobre a aquisição e o arrendamento de terras realizadas por empresas brasileiras cujo controle acionário e controle de gestão estivessem nas mãos de estrangeiros nãoresidentes no território nacional (ADAMS, 2010, p. 2, item 6).

Diante de uma crescente demanda por terras e da constatação de que o Incra não possui mecanismos concretos para efetuar um controle adequado das compras de terras, o grupo de trabalho formado para avaliar tal situação concluiu que era necessária a

\footnotetext{
16 A aprovação da PEC n. 6, eliminando o art. 171 da CF, que fazia distinção entre empresa nacional e estrangeira, influenciou o Parecer GQ n. 181, de 1998, pois a AGU entendeu que, suprimida a distinção, "estaria eliminada a barreira que impedia a fixação, por lei, de restrições à atuação das empresas", reforçando a liberalização da economia também no mercado fundiário (WILKINSON et al., 2010).
} 
revisão dos pareceres de modo a dotar o Estado brasileiro de melhores condições de fiscalização sobre a compra de terras realizada por empresas brasileiras controladas por estrangeiros (ADAMS, 2010, p. 3).

Em 2010, a AGU publicou o parecer n. LA01, de 19 de agosto de 2010, que restabeleceu possibilidades para limitar, ou melhor, para regulamentar os processos de estrangeirização das terras no Brasil. Este documento legal retoma a já citada Lei n. 5.709, de 1971, que regulamentou “a aquisição de imóvel rural por estrangeiro residente no País ou pessoa jurídica estrangeira autorizada a funcionar no Brasil", afirmando que a mesma deve ser acolhida pela Constituição de 1988. Esta lei foi criada para regulamentar a compra de terras por estrangeiros, estabelecendo o limite máximo de compra em 50 módulos (art. $3^{\mathrm{o}}$ ), sendo que a soma das propriedades de uma pessoa estrangeira não pode ultrapassar um quarto (1/4) da área do município (art. 12) (ADAMS, 2010, p. 4) $)^{17}$.

Alfonsin (2010), ao emitir sua avaliação sobre a validade e a abrangência do parecer da AGU em tela, argumenta que a própria Constituição Federal (CF) explicita

dois direitos fundamentais, ligados ao território nacional e titulados pelo seu povo: o primeiro, por óbvio, da soberania sobre a sua terra (art. $1^{\circ}$ parágrafo único da $\mathrm{CF}$ ) e o segundo, o do reflexo necessário dessa soberania na segurança nacional (p. 4) $)^{18}$.

17 É importante observar que a Lei n. 5.709, em seu art. 7ํㅡ, também trata da aquisição de terras na faixa de fronteira, outro tema importante em debate, especialmente no Congresso Nacional, onde há pressões para revisar a lei, reduzindo a chamadafaixa de fronteira do Brasil, atualmente de $150 \mathrm{~km}$.

18 Como adiantamos no primeiro tópico do texto, a retirada do controle sobre a aquisição de terras no Brasil se deu, em parte, pela aprovação da Proposta de Emenda Constitucional (PEC) n. 6, que revogou o art. 171, inciso I, da Constituição, que definia empresa nacional, mas também pelos pareceres de 1994 e 1998, os quais afirmavam a não recepção da Lei n. 7.509, de 1971 pela Constituição de 1988.
A partir desse preceito constitucional, Alfonsin (2010) afirma que

o Parecer aprovado pela Presidência da República, publicado no dia 23 de agosto passado, não teve outro escopo que não o de reconhecer a eficácia das normas constitucionais que defendem e protegem o nosso território e a nossa gente (p. 20),

portanto, é fundamental a adoção de medidas de controle por parte do Estado.

Sem desmerecer a importância jurídica de tal parecer, a solução do problema não se materializa com a referida publicação. Primeiro, há problemas no próprio conteúdo da Lei n. 5.709/71, como, por exemplo, o limite de 50 módulos ou a restrição a um quarto da área do município, pois há municípios imensos no Brasil, especialmente nas regiões Norte e Centro Oeste, principais alvos da busca por terras e expansão do agronegócio (ver HEREDIA et al., 2010).

Em segundo lugar, existe uma distância entre a edição de uma lei (ou parecer) e sua efetividade. Concretamente, o Incra não dispõe de mecanismos eficazes de fiscalização e os cartórios locais não são compelidos a prestar tais informações (sem considerar que muitos, mesmo sob intervenção, continuam operando normalmente), colocando em dúvida o real alcance do dispositivo legal em tela.

Em terceiro lugar, a questão fundiária transcende em muito o problema que se convencionou denominar "farmland grab" ou "grilagem de terras", uma "reação aos efeitos negativos" (NASSAR, 2010) da corrida por terra e a consequente estrangeirização. É fundamental não esquecer os históricos níveis de concentração da propriedade da terra no Brasil, novamente corroborados pelo censo agropecuário de 2006, como salientamos anteriormente. Essa concentração fundiária não será revertida com a adoção de mecanismos de controle da aquisição de terras por estrangeiros, pois a esmagadora maioria das grandes áreas está nas mãos de poucos brasileiros. 


\section{Considerações finais}

O campo brasileiro foi, historicamente, palco de disputas territoriais, não só devido às resistências à expropriação, exploração, ações e demandas populares pelo acesso à terra. As ações e bandeiras das organizações patronais também explicitaram essa disputa, dando especial valor ao território, materializando a aliança entre capital e terra. Essa aliança vem sendo reforçada e ampliada devido à demanda crescente por terras e à entrada de investimentos estrangeiros.

Apesar de ser entendida por alguns como uma oportunidade de negócios, a terra não pode ser reduzida a um ativo e um meio de produção. Além disso, a demanda mundial por terras está em confronto direto com a demanda histórica por reforma agrária, tanto no sentido de disputar um bem finito quanto provocando a alta do preço e o encarecimento das políticas públicas de acesso à terra. Além disso, os investimentos crescentes em ativos fundiários ameaçam a segurança e a soberania alimentar, pois os mesmos concentram ainda mais a produção agropecuária em poucas commodities, favorecendo os monopólios na produção de alimentos e agroenergias.

O crescente volume de aplicações estrangeiras em terras brasileiras tem sido objeto de manifestações contrárias, inclusive de segmentos representativos do agronegócio brasileiro. É interessante notar que mesmo nesses setores que advogam uma perspectiva "pró-mercado", há claramente uma posição de alerta com a quantidade de terras sendo adquiridas por estrangeiros, distanciando-se das recomendações do estudo do Banco Mundial, mais voltadas a explorar as janelas de oportunidades por meio de "investimentos responsáveis".

O parecer da AGU, de 2010, restabeleceu capacidades regulatórias nessa área. No entanto, sem desmerecer a sua importância legal, cujo anúncio causou boa impressão em determinados circuitos internacionais ao mostrar a possibilidade de ação efetiva do Estado em setor tão estratégico, a solução do problema não se encerra com esse instrumento.
A atual inoperância do Estado brasileiro deve ser revertida e a implantação da política de reforma agrária, retomada. Os números de execução orçamentária, de desapropriações de áreas que não cumprem a função social e de assentamento de famílias em projetos de reforma agrária explicitam tal morosidade. Também é fundamental a agilização no reconhecimento dos territórios quilombolas e na demarcação das terras indígenas, políticas públicas que devem ser contabilizadas nessa discussão sobre o acesso à terra no Brasil.

Assim como o território, a terra não representa apenas um meio de produção e sim um lugar de vida e de construção identitária (ser um trabalhador rural, por exemplo) (SAUER, 2010). Nesse sentido, é fundamental aprofundar o debate sobre o "direito dos agricultores familiares camponeses" como um direito humano fundamental de reprodução social e qualidade de vida no campo.

\section{Referências bibliográficas}

ADAMS, L. I. L. Parecer LA-01 Aquisição de terras por estrangeiros. Brasília, Subchefia para Assuntos Jurídicos da Casa Civil da Presidência da República, agosto de 2010 (mimeo).

ALFONSIN, J. T. Apontamento sobre parecer da AGU relacionado com a aquisição de terras rurais do Brasil por empresas estrangeiras e empresas brasileiras com maioria de capital estrangeiro. Porto Alegre, 2010 (mimeo).

ALVIM, A. M. Investimentos estrangeiros diretos e suas relações com os processos, causas e efeitos da concentração e estrangeirização das terras no Brasil. Projeto de cooperação técnica "Apoio às políticas e à participação social no desenvolvimento rural" (PCT IICA/NEAD), Brasília, NEAD, 2009 (relatório de pesquisa).

ARRUDA, R. "Incra acende sinal de alerta contra compra de terras por estrangeiros". In: O Estado de São Paulo, São Paulo, 05 de agosto de 2006.

BANCO MUNDIAL. Rising global interest in farmland: Can it yield sustainable and equitable benefits? Washington D.C., 07 de setembro de 2010.

BATISTA, F. "Cana mantém aquecido mercado de terras". In: O Valor Econômico, São Paulo, p. B12, 02 de agosto de 2010. 
BERTRAND, J. P.; THÉRY, H. e WANIEZ, P. Les Japonais et la mise en valeur des Cerrados au Brésil: pour quelle maitrise de l'espace et de l'approvisionnement alimentaire? In: Économie Rurale, n. 202-203, p. 58-64, 1991.

BORRAS, S. M.; FRANCO, J.; KAY, C. e SPOOR, M. Land grabbing in Latin America and the Caribbean viewed from broader international perspectives.Santiago, Escritório Regional da FAO, versão de 14 de novembro, 2011 (mimeo).

BORRAS, S. M. e FRANCO, J. La política del acaparamiento mundial de tierras: replanteando las cuestiones de tierras, redefiniendo la resistencia. ICAS workingpaper Series, $n$. 001, Transnational Institute, LDPI, ICAS, maio de 2010.

BRANDÃO, A. S. Mercado da terra e estrutura fundiária. In: Brandão, A. S. (org.). Os principais problemas da agricultura brasileira: análise e sugestões. Rio de Janeiro: PNPE/ IPEA, 1988.

BRASIL. Instituto Brasileiro de Geografia e Estatística. Censo agropecuário 2006. Rio de Janeiro, disponível no site http://www.ibge.gov.br/home/estatistica/ economia/ agropecuaria/censoagro/default.shtm. Rio de Janeiro: IBGE, 2009.

BRASIL, Presidência da República. Decreto nº 5.051, de 19 de abril de 2004 - Promulga a Convenção no 169 da Organização Internacional do Trabalho - OIT sobre Povos Indígenas e Tribais, Brasília, 2004 - disponível em www.planalto.gov.br/ccivil_03/_ato2004-2006/2004/ decreto/ d5051.htm(acesso em dezembro de 2010).

BRASIL. MDA - Ministério do Desenvolvimento Agrário. II Plano Nacional de Reforma Agrária: paz, produção e qualidade de vida no meio rural. Brasília: INCRA, 2005.

CHADE, J. "Estrangeiros avançam na aquisição de terras". In: O Estado de São Paulo, 13 de setembro de 2010.

COTULA, L. The international political economy of the global land rush: A critical appraisal of trends, scale, geography and drivers. Journal of Peasant Studies,v. 39, n. 3, mai-2012 (prelo).

DELGADO, G. A questão agrária no Brasil, 1950-2003. JACCOUD, L. (ed.). Questão social e políticas sociais no Brasil contemporâneo. Brasília: IPEA, 2005.

DIAS, G. L. S.; VIEIRA, C. A. e AMARAL, C. M. Comportamento do mercado de terras no Brasil - Proyeto "Mercado de Tierras Rurales". Santiago: CEPAL, 2001.

DUARTE, P. "O apetite dos estrangeiros por terra e petróleo". In: O Globo, 22 de junho de 2008.

FERNANDES, B. M. Estrangeirização de terras na nova conjuntura da questão agrária. Conflitos no campo Brasil 2010. Goiânia, Comissão Pastoral da Terra, p. 76-81, 2011.
FLEXOR, G.; ROCHA, B.; KATO, K. e LIMA, M. S. A economia política do PNPB: uma problemática de ação pública. Rio de Janeiro: IM e CPDA/UFRRJ, 2010 (Relatório de Pesquisa).

HEREDIA, B.; PALMEIRA, M. e LEITE, S. P. Sociedade e economia do "agronegócio" no Brasil. Revista Brasileira de Ciências Sociais, v. 25, n. 74, outubro de 2010.

HECHT, S. B. Soybeans, development and conservation on the Amazon frontier. Development and Change, Institute of Social Studies, v. 36, n. 2, p. 375-404, 2005.

HERVIEU, B. e PURSEIGLE, F. Pour une sociologie des mondes agricoles dans la globalisation. Études Rurales, v. 183, n.1, 2009.

HOFFMANN, R.; NEY, M. Estrutura fundiária e propriedade agrícola no Brasil. Brasília: NEAD/MDA, 2010.

LEITE, S. P. e SAUER, S. Expansión de agronegocios, mercado de tierras y extranjerización de la propiedad rural em Brasil. Mundo Siglo XXI, v. VII, n. 26, p. 43-63, Ciecas, México, 2011.

LEITE, S. P. e WESZ Jr., V. Modèle de développement et dynamiques foncières au Brésil: analyse de l'expansion de l'agribusiness du soja et ses effets sur le millieu rural. Montpellier: CIRAD, 2010 (mimeo).

LEITE, S. P. e ÁVILA, R. V. Um futuro para o campo: reforma agrária e desenvolvimento social. Rio de Janeiro: Vieira \& Lent, 2007.

LEITE, S. P.; HEREDIA, B.; MEDEIROS, L.; PALMEIRA, M. e CINTRÃO, R. Impactos dos assentamentos: um estudo sobre o meio rural brasileiro. São Paulo: Ed. UNESP, 2004.

LIMA, D. L. Estrutura e expansão da agroindústria canavieira no Sudoeste goiano: impactos no uso do solo e na estrutura fundiária a partir de 1990. Campinas: IE/ UNICAMP, 2010, (Tese de Doutorado).

MAISONNAVE, F. "Chinesa estuda compra de áreas na Bahia”. In: Folha de São Paulo, 23 de junho de 2011.

MERLET, M. Les appropriations de terres à grande échelle: analyse du phénomène et propositions d'orientations. Paris, Comité Foncier et Développement, junho de 2010.

NASSAR, A. M. "Terras agrícolas na alça de mira”. In: $O$ Estado de São Paulo, coluna Espaço aberto, p. A2, 20 de outubro de 2010.

O ESTADO de São Paulo. "Editorial: China compra terras no Brasil". São Paulo, p. A3, 03 de agosto de 2010.

ODILLA, F. "Estrangeiros compram 22 campos de futebol por hora". In: A Folha de São Paulo, 02 de novembro de 2010. 
OLIVEIRA, A. U. A questão da aquisição de terras por estrangeiros no Brasil: um retorno aos dossiês. Agrária, no. 12, São Paulo, USP, p. 3-113, 2010.

PELUSO, C. Relatório da Ação Direta de Inconstitucionalidade no 3.239 - Distrito Federal. Brasília, Supremo Tribunal Federal, s/d (mimeo).

PIETRAFESA, J. P.; SAUER, S. e SANTOS, A. E. A. Políticas e recursos públicos na expansão dos agrocombustíveis em Goiás: ocupação de novos espaços em áreas de Cerrado. In: PIETRAFESA, J. P. e SILVA, S. D. (orgs.). Transformação do Cerrado: progresso, consumo e natureza. Goiânia, Editora da PUC Goiás, p. 93-121, 2011.

PRETTO, J. M. Imóveis rurais sob propriedade de estrangeiros no Brasil. Relatório de Projeto de cooperação técnica "Apoio às políticas e à participação social no desenvolvimento rural" (PCT IICA/NEAD), Brasília, NEAD, 2009 (relatório de pesquisa).

RANGEL, I. A questão da terra. Revista de Economia Política, v. 6, n. 4, p. 71-77, out-dez, 1986.

REZENDE, G. Estado, macroeconomia e agricultura no Brasil. Porto Alegre/Rio de Janeiro: EdUFRGS/IPEA, 2003.

SABBATO, A. A intervenção no mercado de terras rurais no Brasil: um estudo sobre o crédito fundiário e o Imposto Territorial Rural no período 1997-2002. Rio de Janeiro: CPDA/UFRRJ, 2008. (Tese de Doutorado).

SAFRANSKY, S. e WOLFORD, W. Contemporary land grabs and their alternatives in the Americas. International Conference on Global Land Grabbing. Universidade de Sussex, 6 a 8 de abril de 2011 - Disponível em www. future-agricultures.org/index (acesso em março de 2012).

SALIM, C. A. As políticas econômica e tecnológica para o desenvolvimento agrário das áreas de cerrados no Brasil: avaliação e perspectivas. Cadernos de Difusão de Tecnologia, v. 2, n. 3, mai-ago, 1986.
SAMPAIO, P. A. et al. Proposta do Plano Nacional da Reforma Agrária, Brasília, MDA/INCRA, outubro de 2003 (mimeo).

SARMENTO, D. Territórios Quilombolas e Constituição: A ADI 3.239 e a Constitucionalidade do Decreto 4.887/03 (parecer). Rio de Janeiro, Ministério Público Federal, Procuradoria Regional da República - $2^{2}$ - Região, março de 2008 (mimeo).

SAUER, S. Demanda mundial por terras: "land grabbing" ou oportunidade de negócios no Brasil? Revista de Estudos e Pesquisas sobre as Américas. Brasília, CEPPAC/ UnB, 2011. (disponível em www.repacm.org).

SAUER, S. "Dinheiro público para o agronegócio". In: Le Monde Diploma tique Brasil, ano 3, n. 33, p. 8-9, abr-2010a.

SAUER, S. Terra e modernidade: a reinvenção do campo brasileiro. São Paulo, Expressão Popular, 2010.

SCOLESE, E. "Aumenta compra de terras brasileiras por estrangeiros". In: Folha da São Paulo, p. A10, 07 de julho de 2008.

TOULMIN, C.; BINDRABAN, P.; BORRAS, J.; MWANGI, E. e SAUER, S. Land tenure and international investments in agriculture. Relatório para o High Level Panel of Experts (HLPE), Comitê de Segurança Alimentar (CFS/ONU). Roma, HLPE Relatório 2, Julho, 2011.

WESZ Jr., V. J. Características e dinâmicas das agroindústrias esmagadoras de soja no Brasil: uma leitura preliminar. Rio de Janeiro: CPDA/UFRRJ, PPGAS/MN/ UFRJ, PPGSA/IFCS/UFRJ. Pesquisa Sociedade e Economia do Agronegócio (Relatório de pesquisa), 2008.

WILKINSON, J.; REYDON, B. e SABBATO, A. Dinâmica do mercado de terras na América Latina: o caso do Brasil. Santiago: FAO/Escritório Regional, dezembro de 2010 (mimeo). 